\title{
Volkanik tüf esaslı geopolimerlerin basınç dayanımına kür süresi ve sıcaklığın etkileri
}

\author{
Effect of curing time and temperature on compressive strength of volcanic tuff-based \\ geopolymer
}

Sevgi ÖZEN*1,a

${ }^{1}$ Recep Tayyip Erdoğan Üniversitesi, Mühendislik Fakültesi, Jeoloji Mühendisliği Bölümü, Rize

\begin{tabular}{lll}
\hline •Geliş tarihi / Received: 23.01.2021 • Düzeltilerek geliş tarihi / Received in revised form: 02.03.2021 Kabul tarihi / Accepted: 15.03 .2021 \\
\hline
\end{tabular}

\begin{abstract}
Öz
Çimento klinkeri üretimi esnasında atmosfere salınan $\mathrm{CO} 2$ gazı sera etkisi nedeniyle küresel ısınmaya neden olmaktadır. Günümüzde bu durum çok tehlikeli boyutlara ulaşmış olup insan yaşamını tehdit eder hale gelmiştir. Bu noktada klinker içermeyen geopolimer üretimi bilim insanları tarafından etkili bir çözüm olarak sunulmaktadır. Bu çalışmada volkanik tüf esaslı geopolimerlerin Portland çimentosuna alternatif kullanım potansiyelleri araştırılmıştır. Araştırma neticesinde volkanik tüf katkılı geopolimerin zeolit içermemesine rağmen makul basınç dayanım değerlerine ulaştığı ve dolayısıyla inşaat sektöründe üretim potansiyelinin bulunduğu tespit edilmiştir. Volkanik tüf esaslı geopolimer dayanımı üzerinde esas etkili mineralin feldispat olduğu, bunun yanında kuvars mineralinin hammaddenin fiziksel özelliklerine etki dolayısıyla geopolimerleşme üzerinde pozitif etkisinin olduğu tespit edilmiştir. Ayrıca, yüksek erken basınç dayanım için yüksek sıcaklıklarda termal kür işlemi, yüksek geç basınç dayanım için ise düşük sıcaklıklarda termal kür işlemi önerilmektedir.
\end{abstract}

Anahtar kelimeler: Basınç dayanım, Geopolimer, Kür süresi, Sıcaklık, Volkanik tüf

\begin{abstract}
During cement clinker production, $\mathrm{CO} 2$ gases released into the atmosphere causes Global warming due to the greenhouse effect. Nowadays, this situation has reached very dangerous levels and threatened the human life. At this point, the production of clinker free-geopolymer is offered by scientist as an effective solution. In this study, the potential of usability of volcanic tuff-based geopolymer to the Portland cement was investigated. As a result of the research, although the volcanic tuff-based geopolymer does not contain zeolite, it has reached reasonable compressive strength values, and therefore has a production potential in the construction sector. It has been determined that the main effective mineral on the strength of volcanic tuff-based geopolymer is feldspar, besides, quartz has a positive effect on the geopolymerization due to the effect on the physical properties of the raw material. In addition, thermal curing at high temperatures is recommended for high early compressive strength achievements, and thermal curing at low temperatures is recommended for high late strength achievements.
\end{abstract}

Keywords: Compressive strength, Geopolymer, Curing time, Temperature, Volcanic Tuff

*a Sevgi ÖZEN, sevgi.ozen@erdogan.edu.tr, Tel: (464) 22375 18, ORCID: 0000-0002-5699-3000 


\section{Giriş}

Portland çimento üretimi, şu an dünyadaki $\mathrm{CO}_{2}$ salınımının \%8'inden sorumlu tutulmaktadır (Shi vd., 2011). Bunun nedeni, 1 ton Portland çimento üretimi neticesinde yaklaşı olarak $800 \mathrm{~kg} \mathrm{CO}_{2}{ }^{\prime}$ in açığa çıkmasıdır (Van Deventer vd., 2012). 2017 y1lında dünya çimento üretimi ortalama olarak 4 milyar tona ulaşmıştır. Bu veri günümüzde çimento üretiminin çok tehlikeli boyutlarda sera etkisine neden olabileceğini göstermektedir. Şu an sahip olunan durumun yanında, artan kentleşme ve yapılaşmadan ötürü çimentoya duyulan ihtiyacın hiç azalmayacağı hatta giderek artacağı böylece çimento üretiminden kaynaklı küresel 1sınma probleminin geri dönülemez boyutlara ulaşacağı aşikârdır.

Yukarıda bahsi geçen nedenlerden ötürü klinker üretimi esnasında oluşan çevresel etkinin azaltılması konusu araştırmacıların ilgisini çekmektedir. Çimento endüstrisinin dünyaya verdiği zarar geri dönülemez boyutlara ulaşmadan önce insanlığın bu konuda önemli adımlar atmasının gerekliliği pek çok kuruluş tarafından kabul edilmektedir. Aslinda klinkerin neden olduğu zararlı etkinin azaltılması için katkılı çimentolar uzun zamandan beri kullanıla gelmektedir. Ancak miktar olarak ele alındıklarında sera gaz etkisini azaltma düzeyine ulaşamamışlardır. Ayrıca katkılı çimento düşük erken dayanım gibi oldukça önemli bir dezavantaja da sahiptir.

Dolayısıyla araştırmacılar katkılı çimentodan daha etkili bağlayıcı malzemelerin arayışına girmişlerdir. Bu yeni nesil malzemeler arasından, geopolimer olarak isimlendirilen malzeme oldukça umut verici niteliktedir (Davidovits, 1994). 1 ton Portland çimento üretimi ile karşılaştırıldığında geopolimerler $\% 90$ oranına kadar $\mathrm{CO}_{2}$ salınımını düşürebilmektedirler. Yangına ve ağır iklim şartlarına dayanıklı yapıların üretimi, uçak endüstrisi, tarihsel yapıların restorasyonu, nükleer atıkların depolanması gibi pek çok potansiyel kullanım alanı bulunan geopolimerlerin günümüzde Portland çimentosuna önemli bir alternatif oldukları düşünülmektedir.

Geopolimerler klinker üretiminde olduğu gibi yüksek sıcaklıklara $\left(1400^{\circ} \mathrm{C}\right)$ ihtiyaç duyulmadan, daha düşük sıcaklıklarda (örneğin $40^{\circ} \mathrm{C}$ ) üretimi yapılabilen ve kısa sürede sertleşebilen amorf ve/veya yarı kristal ve üç boyutlu geopolimerik yapıların bir araya gelmesiyle oluşan inorganik bağlayıcı malzemeler olarak tanımlanmaktadır. Geopolimer başlangıç malzemesi olarak alümina silikat içeriğine sahip doğal veya atık herhangi malzeme kullanılabilmektedir. $\mathrm{Bu}$ nedenle geopolimer hammaddesi olarak uçucu kül, yüksek firın cürufu, atık cam, metakaolin, puzzolanlar ve volkanik tüf gibi çok çeşitli hammadde kaynakları kullanılabilmektedir.

Türkiye volkanik tüf kaynakları bakımından oldukça zengin bir ülkedir. Tüf, volkanik patlama neticesinde açığa çıkan küllerden oluşan bir kaya türüdür (Fisher ve Schmincke, 1984). İçerisinde ikincil olarak bulunan ve kayaca endüstriyel değerini veren zeolit oluşumları yaygındır. Literatürde farklı zeolitlerin (klinoptilolit, mordenit, analsim) geopolimerleşmelerinin araştırıldığı çalışmalar oldukça yaygındır (Villa vd., 2010; Tekin, 2016; Nikolov vd., 2020; Özen ve Alam, 2018; Baykara vd., 2017; Güngör, 2019). Ancak literatürde söz konusu tüflerin zeolit içermeyen eşlenikleri hakkında kısıtlı sayıda veriler mevcuttur (Ekinci vd., 2019). Volkanik tüflerin içerisinde geopolimerleşmeye katkısı olan zeolit dışında başka mineraller de bulunabilmektedir. $\mathrm{Bu}$ nedenle çalışmanın amacı zeolit içermeyen volkanik tüflerin geopolimer üretimine uygun olup olmadığının araştırılmasıdır. Ayrıca zeolit içermeyen volkanik tüf katkılı geopolimerlerin basınç dayanım özelliklerine kür süresi ve sıcaklığının etkisini incelemek böylece bu malzemeden üretilen geopolimerlerin inşaat alanında kullanım potansiyellerini ortaya koymaktır.

\section{Materyal ve metot}

Araştırmada geopolimer hammaddesi olarak kullanılan volkan tüfü, Bayburt Taşı olarak da adlandırılan ve volkano-sedimanter kayaçlardan meydana gelen (Eosen yaşl1) Yazyurdu Formasyonu'nun içerisinde bulunan tüf tabakalarından temin edilmiştir (Şekil 1). Örnekler yol kenarına yakın şekilde yüzeyleyen tüf tabakalarından alınmıştır. Bayburt Tüfünün içerisinde zeolit oluşumları olabileceğinden farklı bölgelerden örnek temini yapılıp laboratuvarda XRD analiz ile zeolit içerip içermedikleri araştırılmıştır. Analiz neticesinde içerisinde zeolit bulunmayan yaklaşı $10 \mathrm{~kg}$ kadar tüf örneği öncelikle çeneli kırıcı ile yaklaşı 2-3 cm boyutuna indirgenmiştir. Ardından bilyeli değirmen ile 100 mikron elekten tanelerin tamamı geçecek şekilde ögütülmüştür. Bayburt Tüfünün kimyasal analizi $\mathrm{XRF}$ analizi ile tayin edilmiştir. İçerisinde bulunan fazların miktarı ise kantitatif X-ray difraksiyon (QXRD) analizi ile saptanmıştır (Philips PW 1730 difraktometre, $\mathrm{CuK} \alpha$ radiation, $40 \mathrm{kV}, 30 \mathrm{~mA}$ ). 


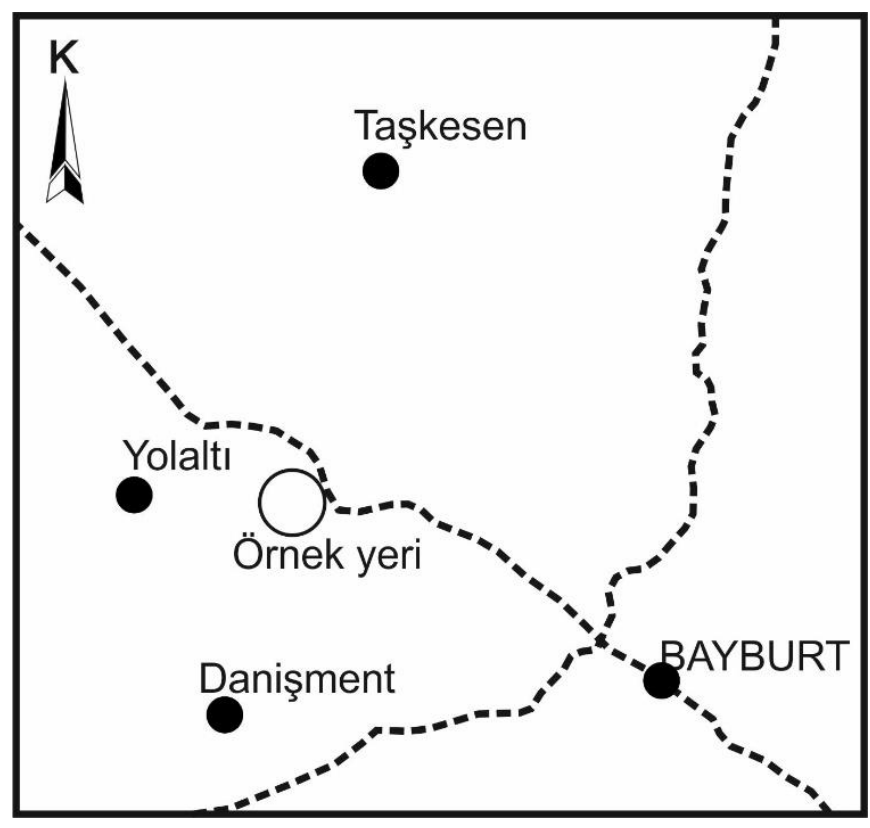

Şekil 1. Bayburt Tüfü'nün yer bulduru haritas1

Çalışma esnasında Bayburt Tüfünü aktive etmek için alkali aktivatör olarak sodyum silikat $\left(\mathrm{Na}_{2} \mathrm{SiO}_{3}\right)$ ve sodyum hidroksit $(\mathrm{NaOH})$ kullanılmıştır. Cam suyu olarak da adlandırılan ve siv1 formda bulunan sodyum silikat $\left(\mathrm{SiO}_{2}\right.$ : \% 27.7; $\left.\mathrm{Na}_{2} \mathrm{O}: \% 9.8 ; \mathrm{H}_{2} \mathrm{O}: \% 62.5\right)$ tüf karışımın içerisine direk eklenmiştir. Pellet şeklinde temin edilen (\%98 saflıkta) sodyum hidroksit $(12 \mathrm{M})$ ise karışıma eklenmeden bir gece önce damıtılmış su ile çözelti haline getirilerek kullanıma hazır hale getirilmiştir.

Portland çimentosunun aksine geopolimer karışımları hazırlanırken başlangıç malzeme farklılıkları, kullanılan solüsyon farklılıkları gibi nedenlerden ötürü standart bir yöntem uygulanamamaktadır. Bunun yerine genel olarak kabul görmüş ve her bir örnek için aynı şekilde uygulanan karışım metodu yapılmaktadır. Geopolimer pastalarının hazırlanması esnasında Bayburt Tüfüne öncelikle sodyum hidroksit solüsyonu eklenmiş ve karışım yaklaşık olarak 2-4 dakika kadar karıştırılmıştır. Daha sonra meydana gelen homojen karışıma sodyum silikat eklenmiş ve karışım ilave 2-4 dakika kadar daha karıştırılmıştır. Karışımlarda tüf/aktivatör oranı 2 ve $\mathrm{Na}_{2} \mathrm{SiO}_{3} / \mathrm{NaOH}$ oranı 2 olarak kullanılmıştır. Karışımlar küp kalıplara $(5 \times 5 \times 5 \quad \mathrm{~cm})$ yerleştirildikten sonra etüve konulmuştur. Üretilen geopolimerlere kür sıcaklığının etkisini incelemek için $40^{\circ} \mathrm{C}$ ve $90^{\circ} \mathrm{C}$ olmak üzere iki farklı sıcaklık etkisi uygulanmıştır. Kür süresi olarak ise 7, 28, 56 ve 90 günlük kür süreleri uygulanmıştır. Basınç dayanım analizleri üç adet küp numunesi üzerinde 7, 28, 56 ve 90 günlerde yapılmıştır.

\section{Bulgular ve tartışma}

\subsection{Karakterizasyon}

Bayburt Tüfü'nün kimyasal oksit değerleri Tablo 1 'de verilmiştir. Toplam $\mathrm{SiO}_{2}$ ve $\mathrm{Al}_{2} \mathrm{O}_{3}$ değeri \% 83.5 'dir. Geopolimerleşme açısından malzemenin silika ve alümina değerlerinin yüksek olması reaksiyon açısından olumlu bir durum olarak değerlendirilmektedir. Tablo 1'den de görüldüğü üzere Bayburt Tüfü'nün reaktif silika ve alümina değeri oldukça yüksektir. Bu değerler malzemenin geopolimerik olarak aktif olacağını gösteren kanıt niteliğindedir. Tablo 1'e bakıldığında ayrıca $\mathrm{K}_{2} \mathrm{O}$ ve $\mathrm{Na}_{2} \mathrm{O}$ değerlerinin de yüksek olduğu görülmektedir.

Tablo 1. Bayburt Tüfü'nün kimyasal kompozisyon değerleri

\begin{tabular}{|ccccccccc|}
\hline \multicolumn{7}{|c|}{ Kimyasal Analiz (\%) } \\
\hline $\mathrm{SiO}_{2}$ & $\mathrm{Al}_{2} \mathrm{O}_{3}$ & $\mathrm{Fe}_{2} \mathrm{O}_{3}$ & $\mathrm{CaO}$ & $\mathrm{MgO}$ & $\mathrm{K}_{2} \mathrm{O}$ & $\mathrm{Na}_{2} \mathrm{O}$ & L.O.I. & Toplam \\
71.2 & 12.3 & 1.33 & 2.69 & 1.25 & 3.49 & 3.74 & 4 & 100 \\
\hline
\end{tabular}

Bayburt Tüfü’nün mineralojik faz içerikleri (kantitatif) Tablo 2'de verilmiştir. Tablo 2 incelendiğinde başlangıç malzemesinin içerisinde başlica kuvars, feldispat ve mika 
mineralinin bulunduğunu görülmektedir. $\mathrm{Bu}$ minerallerden kuvarsin literatürde geopolimerik olarak aktif olmadığ bilinmektedir (Kohout ve Koutnik, 2020). Ancak her ne kadar geopolimerik olarak aktif olmasa da sisteme kendi sertlik derecesinden ötürü tüfün ögütme esnasındaki fiziksel özelliklerine etkisinin olabileceği düşünülmektedir. K-feldispat ve plajiyoklas geopolimerik aktiviteleri yüksek minerallerdir. İki mineral kıyaslandığında, K-feldispatın içerdiği K iyonu dolayısıyla plajiyoklasa göre daha reaktif olduğu bilinmektedir. Mika ise geopolimerik yönden aktif bir mineral değildir. Bu nedenle Bayburt Tüfünün içerisinde yüksek oranlarda bulunsa bile reaksiyona katkısının olmayacağ1 bilinmektedir. Geriye kalan kaolinit ve kalsit mineralleri geopolimerik olarak aktif mineraller olmalarına rağmen miktar olarak düşük (yaklaşık \%5) olduklarından reaksiyon üzerinde çok fazla etkilerinin olamayacağ 1 düşünülmektedir.

Tablo 2. Bayburt Tüfünün kantitatif X-ray difraksiyon (XRD) analizi

\begin{tabular}{|l|ccccccc|}
\hline \multicolumn{8}{|c|}{ Mineralojik Kompozisyon (\%) } \\
\hline & Kuvars & K-feldispat & Plajiyoklas & Mika & Kaolinite & Kalsit & Toplam \\
\hline Bayburt Tüfü & 32 & 18 & 26 & 13 & 5 & 6 & 100 \\
\hline
\end{tabular}

Yukarıda yapılan açıklamaların 1 şı ğı altında malzemelerin reaksiyonlarını yorumlamada içerisinde bulunan minerallerin ne olduğunu saptamanın yanında bu minerallerden ne kadar bulunduğunun tespitinin de önemli olduğunu görmekteyiz. Ĕger minerallerin karakterizasyonu sadece XRD analizi ile fazların ne olduğunun tespit edilmesiyle sinırlı kalsayd, kaolinitin geopolimerik reaksiyona katıldığ 1 kanısına varılacaktı. Ancak, kantitatif XRD analizi neticesinde tüfün içerisinde kaolinitin $\% 5$ oranında bulunduğunun saptanmasiyla reaksiyona katılımının çok önemli oranlarda olamayacağını söylenebilir. Bu nedenle geopolimerik reaksiyonu doğru yorumlamak için hammaddelerin kantitatif olarak mineral tayinlerinin yapilmas önerilmektedir.

\subsection{Basınç dayanım analizi}

Literatürde, doğal puzolanlardan olan volkanik tüflerin zeolit içeren varyasyonlarının basınç dayanım özellikleri incelenmiştir. Bu çalışmalar arasından Villa vd., (2010), 7 Molarlık sodyum hidroksit çözeltisi kullanarak, tüf/aktivatör oran 10 olan ve $40^{\circ} \mathrm{C}$ 'de 90 gün süreyle termal kür prosesi uyguladığ 1 klinoptilolit esaslı geopolimerler için en yüksek basınç dayanım değerini $38 \mathrm{MPa}$ olarak saptamıştır. Nikolov vd., (2020) ise kullanımdan önce $900^{\circ} \mathrm{C}$ 'de kalsinasyon işlemine maruz bıraktığ1 klinoptilolit içeren tüfleri potasyum hidroksit $(\mathrm{KOH})$ ve potasyum silikat $\left(\mathrm{K}_{2} \mathrm{SiO}_{3}\right)$ ile aktive ettikten sonra 3 gün süreyle $80^{\circ} \mathrm{C}$ 'de termal kür işlemine maruz bırakmış ve en yüksek basınç dayanım değerini $43 \mathrm{MPa}$ (28 günlük) olarak saptamıştır. Her ne kadar Nikolov vd., (2020)'nin çalışmasında yüksek dayanım değerlerine ulaşılsa da malzemeyi önce kalsine etmek daha sonra tekrar termal kür işlemine maruz bırakmak geopolimer kullanımının temel amacı olan $\mathrm{CO}_{2}$ salınımını azaltma prensibine ters düşmektedir. $\mathrm{Bu}$ çalışmalarda üretilen geopolimerlerin basınç dayanımını veren faz, kullanılan doğal volkanik tüflerin içerisinde bulunan klinoptilolit mineralidir. Klnoptilolit minerali ayn1 zamanda katk1lı çimentolarda da kullanılmaktadır. Bu çalışmada kullanılan volkanik tüfün içerisinde ise klinoptilolit bulunmamaktadır. Buna rağmen Şekil 1'de gösterilen basınç dayanım verilerine dayanarak malzemenin en az klinoptilolit içeren eşlenikleri kadar aktif olduğunu görülmektedir. Şöyle ki $40^{\circ} \mathrm{C}$ 'de 28 gün süreyle termal kür işlemine maruz bırakılan Bayburt Tüfü esaslı geopolimerin basınç dayanım analiz sonucu $23 \mathrm{MPa}$ 'dır. Bayburt Tüfü esaslı geopolimerin en yüksek basınç dayanım değeri ise $\left(40^{\circ} \mathrm{C}\right.$ 'de 90 günlük termal kür işlemine tabi tutulan) $30 \mathrm{MPa}$ 'dir.

Şekil 1'de verilen analiz sonuçlarına göre kür süresi ve kür sıcaklığının volkanik tüf katkılı geopolimerlerin basınç dayanım değerleri üzerinde oldukça etkili parametreler olduğunu görülmektedir. Aşağıda bu parametrelerin geopolimerler üzerindeki etkileri sırasıyla incelenmiştir. 


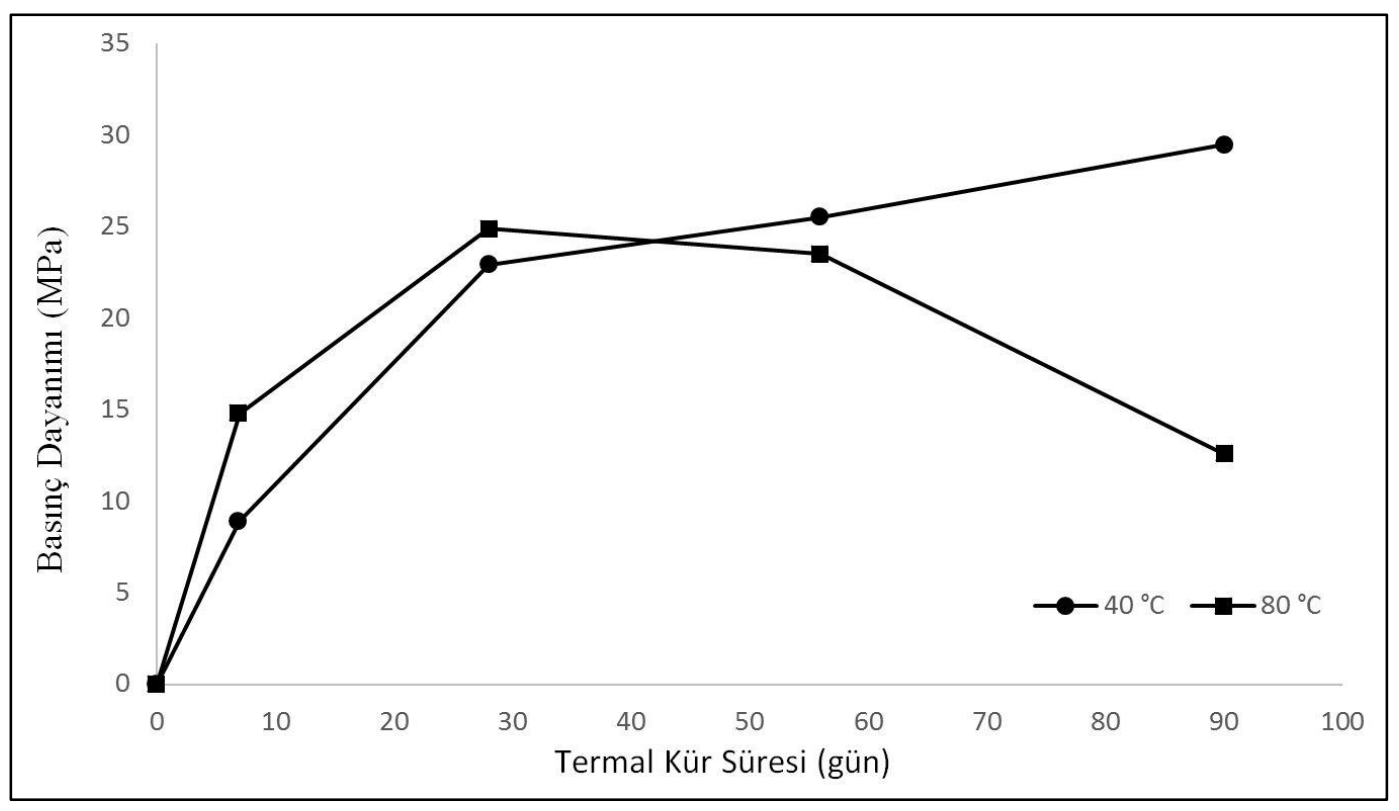

Şekil 2. Volkanik tüf esaslı geopolimerlerin basınç dayanımları

\subsubsection{Kür sıcaklığı ve kür süresinin etkisi}

Yapılan araştırmalara dayanarak kür süresi olarak $40^{\circ} \mathrm{C}$ ve $80^{\circ} \mathrm{C}$ seçilmiştir. Bu değerlerden düşük kür sıcaklığ 1 olan $40^{\circ} \mathrm{C}$ 'nin tercih edilmesinin nedeni, geopolimerlerin üretim amacının $\mathrm{CO}_{2}$ salınımını azaltmak olduğundan literatür bilgilerine dayanarak en düşük ve en etkili sıcaklığın seçilmeye çalışılmasıdır. Diğer bir sıcaklık etkisi olan $80^{\circ} \mathrm{C}$ 'nin seçilmesinin nedeni ise genellikle geopolimer üretimlerinde meydana gelen düşük erken dayanım gelişimi dezavantajının yüksek termal sıcaklık ile giderilmeye çalışılmasındandır.

Analiz sonuçlarını incelendiğinde öncelikle Bayburt Tüfü'nün klinoptilolit içermemesine rağmen geopolimerik olarak oldukça aktif olduğunu görülmektedir (Şekil 2). Bunun nedeni Bayburt Tüfü'nün içerisinde toplam olarak $\% 44$ miktarında bulunan feldispat mineralidir. Feldispat minerali literatürde aktif bir malzeme olarak saptanmıştır (Xu ve van Deventer, 2002). Ayrica Bayburt Tüfü esaslı geopolimerin içerinde feldispat minerallerine ek olarak bulunan \%32 miktarındaki kuvars mineralinin de geopolimerleşme üzerinde direk reaksiyona katılım yolundan ziyade ögütme esnasında kayacın tane boyut dağılımının kontrolü, kayacın su ihtiyacının kontrolü gibi parametrelere etkisi dolayısıyla olabileceği kanısına varılmıştır. Araştırmacının önceki çalışmalarına dayanarak daha düşük kuvars içerikli volkanik tüf çalışmalarına kıyasla, kuvars içeriği fazla olan geopolimerin çok daha kolay işlenebildiği ve kalıplara yerleştiği gözleminde bulunmuştur.
Ayrica kuvars mineralinin geopolimerik reaksiyona dolaylı etkisinin incelenmesi ileriki çalışmalar olarak önerilmektedir.

Şekil 2'i incelendiğinde kür sıcaklığının geopolimer üretiminde oldukça etkili bir parametre olduğunu görülmektedir. Volkanik tüf esash geopolimer $40^{\circ} \mathrm{C}^{\prime}$ de 7 gün süreyle termal kür işlemine maruz bırakılırsa düşük basınç dayanım elde edilebilmektedir (9 $\mathrm{MPa})$. Ancak ayn geopolimer örneği $80^{\circ} \mathrm{C}$ 'de 7 gün termal olarak kürlenirse daha yüksek basınç dayanım elde edilebilmektedir (15 MPa). Bayburt Tüfü esasl1 geopolimer için kür sıcaklığının 28 günlük pastalar üzerindeki etkisi yükselerek devam etmiştir. Şöyle ki $40^{\circ} \mathrm{C}^{\prime}$ de 28 gün süreyle termal kür işlemine maruz bırakılan geopolimerin basınç dayanımı oldukça artmış (23 MPa) ancak $80^{\circ} \mathrm{C}^{\prime}$ de 28 gün süreyle termal olarak kürlenen geopolimerin basınç dayanımından (24 $\mathrm{MPa})$ biraz daha düşük çıkmıştır. $\mathrm{Bu}$ dayanım davranışı kür süresi ilerledikçe tersi duruma dönmüştür. $40^{\circ} \mathrm{C}$ 'de 56 gün süreyle termal kür işlemine tutulan geopolimer $26 \mathrm{MPa}$ basınç dayanımına ulaşırken, $80^{\circ} \mathrm{C}$ 'de 56 günlük termal kürlemeye maruz birakılan geopolimerin basınç dayanım değerinde (24 MPa) düşüş saptanmıştır. $\mathrm{Bu}$ düşüş termal kür süresi 90 güne çıkarıldığında çok daha bariz şekilde görülmektedir (Şekil 2). Ayrıca diğer bir önemli veri, $80^{\circ} \mathrm{C}$ 'de termal kür işlemine tabi tutulan geopolimer için, kür süresi ilerledikçe basınç dayanımında kararlı davranıştan ziyade negatif yönde azalım tespit edilmiştir. Özellikle $80^{\circ} \mathrm{C}$ 'de 90 gün süreyle termal kür işlemine maruz bırakılan geopolimer basınç dayanım değerlerinde oldukça yüksek miktarda düşüşler saptanmıştır. Bunun 
nedeninin yüksek sıcaklıklarda termal kür işlemi esnasında geopolimerin içerisinde bulunan solüsyondan kaynaklı nemin hızlı bir şekilde ortamdan uzaklaşması ve reaksiyon için gerekli alkali ortamın devam edememesinden kaynaklı olduğu düşünülmektedir. Tüm bu bulgular dahilinde yüksek erken dayanım eldesi için yüksek termal kür sicaklığı ve erken termal kür süresi, yüksek geç dayanım değerleri eldesi için ise düşük termal kür sıcaklığı ve geç termal kür süreleri tavsiye edilmektedir.

\subsection{Volkanik tüf esaslı geopolimerin mikro yapısal analizi}

Taramalı elektron mikroskopisi (SEM) aracıllı̆ııla Bayburt Tüfü esaslı geopolimerin mikro yapısal özellikleri incelenmiştir. Şekil 3'te görüldüğü üzere geopolimer pastasının termal kür işlemi esnasında içerisinde yaklaşı $25 \mu \mathrm{m}$ çapında hava kabarcığının hapsolduğu görülmektedir. Geopolimer pasta ya da harç hazırlama esnasında hava kabarcıklarının oluşması kaçınılmaz bir durumdur. $\mathrm{Bu}$ boşlukların dayanım üzerinde negatif etkisinin olduğu düşünülmektedir.

Şekli 3'te dikkat çeken diğer bir durum ise geopolimer ürünlerinin farklı gir tonlarında gözükmeleridir. Bilindiği üzere SEM incelemelerinde daha açık bölgeler daha yüksek atom numarasına sahip fazları, daha koyu gözüken bölgeler ise daha düşük atom numaralı fazları işaret etmektedir. Buna dayanarak Şekil 3 'te ayırt edilen en açık fazların Ca'ca zengin geopolimer ürün olma ihtimali yüksektir. Bu ürün muhtemelen Bayburt Tüfünün içerisinde bulunan Ca'ca yüksek plajiyoklas ile alkali çözeltinin girmiş olduğu reaksiyon neticesinde oluşan C-S-H fazıdır. Ancak daha kesin bir sonuca ulaşmak için SEM analizinin yanında kimyasal içeriğe işaret eden EDX analizi de önerilmektedir. Geriye kalan daha koyu görünümlü alanların ise diğer bir geopolimer ürünü olan geopolimerik jel olma olasılı̆̆ yüksektir. Zira geopolimere esas basınç dayanım değerlerini veren geopolimer ürün amorf ve/veya yarı amorf faz olan geopolimerik jeldir.

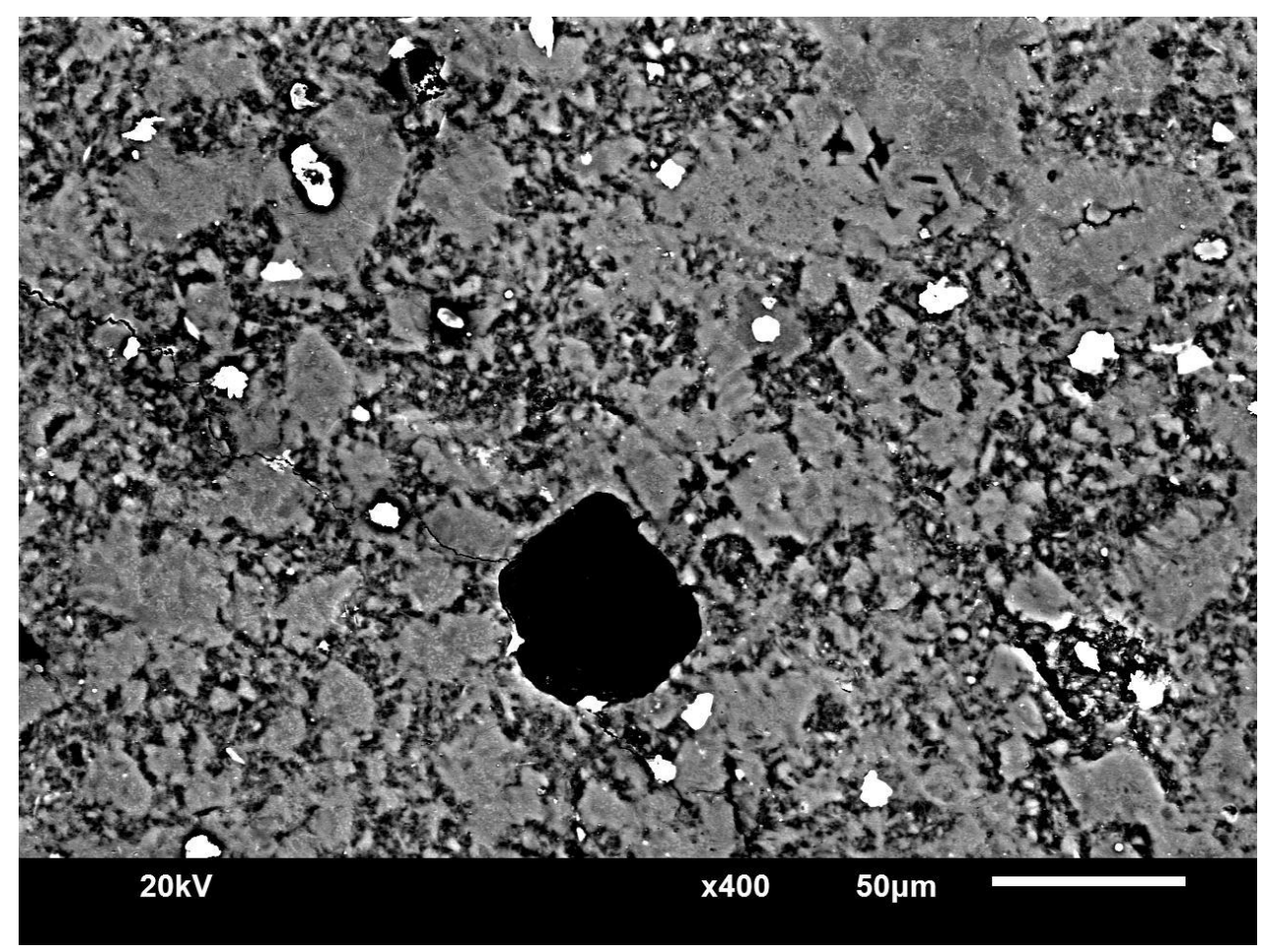

Şekil 3. Volkanik tüf esaslı geopolimerlerin 28 günlük SEM görüntüsü.

\section{Sonuç ve Öneriler}

Yapılan çalışma neticesinde ulaşılan sonuçlar ve ileriki çalışmalar için yapılan öneriler aşağıda verildiği gibidir:

- Volkanik Tüf esaslı geopolimerin inşaat alanında kullanılabilirliği mevcuttur.
- En yüksek basınç dayanım değeri $40^{\circ} \mathrm{C}^{\prime} \mathrm{de}$ kürlenen geopolimer için ( 90 günlük) $30 \mathrm{MPa}$ olarak tespit edilmiştir.

- Geopolimerik reaksiyon gelişimine toplamda \%44 oranında bulunan feldispat minerallerinin neden olduğu saptanmıştır. 
- Kuvars mineralinin geopolimerik reaksiyona katılımından ziyade kayacın fiziksel özellikleri üzerindeki kontrolü sayesinde pozitif etkisinin olabileceği sonucuna varılmıştır.

- Erken dönemde yüksek basınç dayanımı için yüksek sıcaklıklarda kür işlemi, geç dönemde yüksek basınç dayanım için ise düşük sıcaklıklarda kür işlemine ihtiyaç belirlenmiştir.

Farklı feldispat grubu minerallerinin (ortoklas, albit) geopolimerik yönden karşılaştırılmaları böylece farklı katyonların ( $\mathrm{Na}, \mathrm{K})$ geopolimerik reaksiyon üzerindeki etkilerinin saptanması ileriki çalışmalar olarak önerilmektedir.

\section{Kaynaklar}

Baykara, H., Cornejo, M.H., Murillo, R., Gavilanes, A., Paredes, C. and Elsen J. (2017). Preparation, characterization and reaction kinetics of green cement: Ecuadorian natural mordenite-based geopolymers. Materials and Structures, 50, 188200, https://doi.org/10.1617/s11527-017-1057-z.

Davidovits, J. (1994). Properties of geopolymer cements. In: First International Conference on Alkaline Cements and Concretes, Kiev, Ukraine. pp. 131-149.

Ekinci, E., Türkmen, İ., Kantarcı, F. and Karakoç, M.B. (2019). The improvement of mechanical, physical and durability characteristics of vpşcanic tuff based geoplymer concrete by using nano silica, micro silica and Styrene-Butadiene Latex additives at different ratios. Construction and Building Materials, 201, 257-267, https://doi.org/10.1016/j.conbuildmat.2018.12.2 04.

Fisher, R.V. and Schmincke, H.U. (1984). Pyroclastic rocks. Springer Verlag, 472 pp.

Güngör, D. (2019). Doğal zeolit-bazlı geopolimerlerin özellikleri. Yüksek Lisans Tezi, Recep Tayyip Erdoğan Üniversitesi, Fen Bilimleri Enstitüsü, Rize.
Kohout, J. and Koutnik, P. (2020). Effect of filler type on the thermo-mechanical properties of metakaolinite-based geopolymer composites. Matreials, 13(10), 2395, https://doi.org/10.3390/ma13102395.

Nikolov, A., Nugteren, H. and Rostovsky, I. (2020). Optimization of geopolymers based on natural zeolite clinoptilolite by calcination and use of aluminate activators. Construction and Building Materials, 243, 118257, https://doi.org/10.1016/j.conbuildmat.2020.1182 57.

Özen, S. and Alam, B. (2018). Compressive strength and microstructural characteristics of natural zeolitebased geopolymer. Periodica Polytechnica Civil Engineering, 62(1), 64-71, https://doi.org/10.3311/PPci.10848.

Shi, C., Jimenez, A.F. and Palomo, A. (2011). New cements for the 21st century: The pursuit of an alternative to Portland cement. Cement and Concrete Research, 41, 750-763, https://doi.org/10.1016/j.cemconres.2011.03.01 6.

Tekin, İ. (2016). Properties of $\mathrm{NaOH}$ activated geopolymer with marble, travertine and volcanic tuff wastes. Construction and Building Materials, 127 , 607-617, https://doi.org/10.1016/j.conbuildmat.2016.10.0 38.

Van Deventer, J.S.J., Provis, J.L. and Duxson, P. (2012). Technical and commercial progress in the adoption of geopolymer cement. Minerals Engineering, 29, 89-104, https://doi.org/10.1016/j.mineng.2011.09.009.

Villa, C., Pecina, E.T., Torres, R. and Gomez, L. (2010). Geopolymer synthesis using alkaline activation of natural zeolite. Construction and Building Materials, 24, 2084-2090, https://doi.org/10.1016/j.conbuildmat.2010.04.0 52.

Xu, H. and van Deventer, J.S.J. (2002). Factors affecting the geopolymerization of alkali-feldspars. Minerals and Metallurgical Exploration, 19,209214, https://doi.org/10.1007/BF03403271. 